\title{
Continuous Real-time Detection of Microbial Contamination in Water using Intrinsic Fluorescence
}

\author{
Aminata P. Kilungo ${ }^{1 *}$, Njeri Carlton-Carew ${ }^{2}$ and Linda S. Powers ${ }^{3}$ \\ ${ }^{1}$ Department of Soil, Water and Environmental Science, University of Arizona, USA \\ ${ }^{2}$ Department of Chemical and Environmental Engineering, University of Arizona, USA \\ ${ }^{3}$ Department of Electrical and Computer Engineering and Department of Biomedical Engineering, University of Arizona, Tucson AZ 85721 , USA
}

\begin{abstract}
With the rapid increase in global population, geographically changing drought conditions and the ensuing potential water shortage, water quality has become a major concern. In some extreme cases, such as Arizona, the population may have to switch and use recycled toilet water for potable use in the near future. However, our current monitoring methods for drinking water do not provide fast and reliable results to deal with these challenges. By using intrinsic fluorescence, microbial contamination in water can be monitored in real-time, continuously, without sample collection or contact and at very low concentration. The detection limit of the instrument designed specifically for this purpose and reported here is $\sim 50$ bacterial cells/L. By monitoring the fluorescence of cellular components of microorganisms, their concentrations and metabolic states (live, dead, spores) can be determined. These fluorophores include reduced pyridine nucleotides (RPNs), flavins, and cytochromes to distinguish live cells: cytochromes for dead cells; and calcium dipicolinic acid (DPA) for spores. By using this method, a wide range of microorganisms such as bacteria, protozoa, amoebae, fungi and other microorganisms can be detected.
\end{abstract}

Keywords: Intrinsic fluorescence of microbes; Real-time monitoring; Microbe detection; Water monitoring

Abbreviations: DPA: Dipicolinic Acid; RPN: Reduced Pyridine Nucleotides; LED: Light Emitting Diode; PMT: Photomultiplier Tube; UV: Ultraviolet Light

\section{Introduction}

Clean water is crucial for human health. With the growth of the global population, the scarcity of our most precious natural resource, clean water has become an issue. However, this importance is at a very different magnitude and scale in different parts of the world. In the southwestern part of the United States, this problem is imminent. Over 30 million people in California, Arizona and Nevada depend on the Colorado River for their water supply [1]. However, the lower Colorado River basin is facing a water shortage [2,3]. One of the solutions to this problem is to treat and reuse water of impaired quality (e.g., wastewater for potable use). One of the obstacles to direct potable reuse of wastewater is the need for rapid assessment of the microbial contamination of the treated water. Domestic wastewater contains a wide variety of waterborne pathogens (viruses, bacteria, and protozoa). These pathogens include Vibrio cholerae, Shigella dysenteriae, Escherichia coli 0517:H7, Salmonella typhi, Hepatitis A virus, Cryptosporidium parvum oocysts, and Giardia lamblia cysts [4]. Most analytic methods for the assessment of these pathogens require $18 \mathrm{hrs}$ or longer and none can be used continuously. More rapid methods for microbial load and pathogen detection are needed to ensure the quality of the treated water if it is to be used for potable purposes.

While there is a wide range of methods that have been developed to detect microbes in water, they all suffer from a number of limitations. One of the most rapid methods available for detection of microbial contamination in drinking water is PCR (polymerase chain reaction). PCR suffers from a number of limitations: 1) does not determine viability of the organism, 2) interference from solutes in the water, 3 ) only small volumes can be assayed (10 to 100 microliters), 4) specific primers required for each organism or groups of organisms, and 5) recovery and purification of DNA from low numbers of microorganisms is problematic [5-7]. Another limitation is the sampling method.
Currently, we do a blind sampling or subsample from high or flowing volumes, which may not be representative of the water contamination.

\section{Intrinsic fluorescence}

The use of intrinsic fluorescence to study cellular metabolic components has been explored since the 1950s [8-10]. Remote, realtime detection and quantification of live cells, dead cells, and spores in fluids (air, water) and on surfaces and sub-surfaces (like those of food, surgical theaters, soils, rock, ice) at low concentrations has been demonstrated [11-13]. Some microbes have demonstrated specific fluorescence signatures that depend on their environment or growth conditions [14], e.g., Escherichia coli, Enterococcus faecalis and Staphylococcus aureus in otitis media and contamination source tracking of several Pseudomonas spp. in dairy products [15]. Our approach makes use of the following metabolic intrinsic fluorescence signatures to detect the presence of microbes that are present under physiological conditions: reduced pyridine nucleotides (RPNs), flavins, cytochromes, calcium dipicolinic acid (DPA) and others [11-13,15-17]. Metabolic signals, which are indicators of live cells, fluoresce in the bluegreen region with $340-360 \mathrm{~nm}$ excitations. The fluorescence emitted is directly proportional to the concentration of metabolites and thus to the average number of live cells [11]. Flavins and protoporphyrin IX, which also fluoresce in the red region upon 565-595 nm excitations, are found in both live and dead cells. Cytochromes fluoresce in the near IR upon 610-640 nm excitations. Excitations in the deep UV (e.g., 250-300

*Corresponding author: Aminata P. Kilungo, Department of Soil, Water and Environmental Science, University of Arizona, P. O. Box 2100038, Tucson AZ 85721-0038, USA, Tel: 520-449-1832; E-mail: paminata@email.arizona.edu

Received February 27, 2013; Accepted March 14, 2013; Published March 16, 2013

Citation: Kilungo AP, Carlton-Carew N, Powers LS (2013) Continuous Real-time Detection of Microbial Contamination in Water using Intrinsic Fluorescence. J Biosens Bioelectron S12: 002. doi:10.4172/2155-6210.S12-002

Copyright: @ 2013 Kilungo AP, et al. This is an open-access article distributed under the terms of the Creative Commons Attribution License, which permits unrestricted use, distribution, and reproduction in any medium, provided the original author and source are credited. 
$\mathrm{nm}$ ) produce fluorescence from a variety of biological molecules (e.g., aromatic amino acids), which are also found in dust, pollen, smog, and other environmental substances. While similar instruments using this approach have been used to demonstrate detection and quantification of microorganisms on surfaces [13], this paper will discuss the proofof-concept for using this technology to continuously monitor drinking water in real-time as a public health measure.

Intrinsic fluorescence technology has several advantages over other rapid methods. It is less costly than PCR, no sample contact is required and water monitoring can be done continuously and in real-time with high sensitivity. Based on our initial experiments with a prototype instrument reported here, the detection limit for viable bacteria is $\sim 50$ cells/L. While the method does not identify the microbes, it immediately identifies changes in total microbial load and hence the water quality caused by environmental conditions or failure in the water distribution system. This system can also direct where and when to sample when such events occur. There are technologies that can be used simultaneously with the intrinsic fluorescence technology for identification of microorganisms of interest. One such method that has been demonstrated is the use of cell-capture technology using surfacebound ligands $[13,18]$.

\section{Methods}

\section{Intrinsic fluorescence technology}

The fluid prototype instrument, shown in Figures 1 and 2 is similar

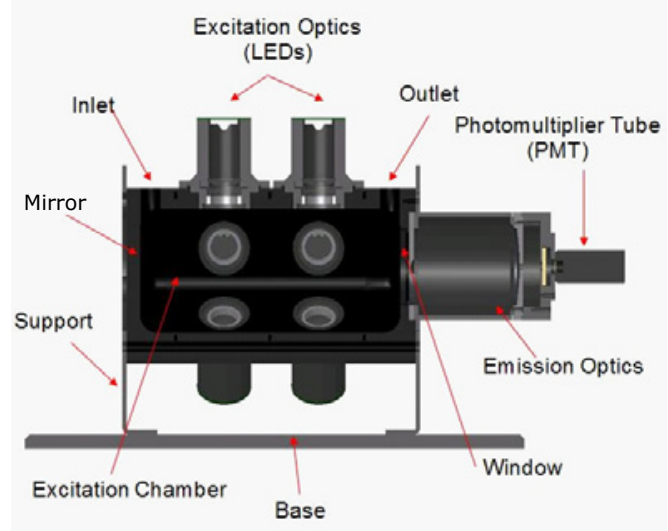

Figure 1: Intrinsic fluorescence instrument for water monitoring.

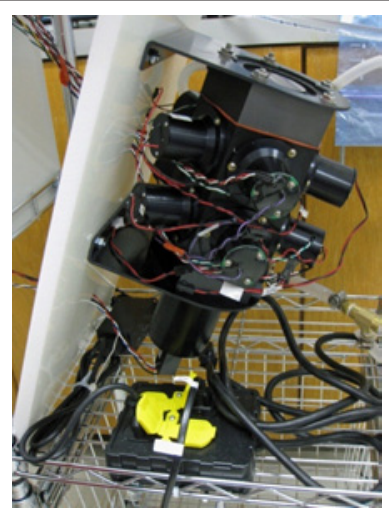

Figure 2: Intrinsic fluorescence instrument for water monitoring (shown schematically in Figure 1). in design to those reported previously [11-13] for surfaces except that the optical arrangement places the excitation light at right angles to the fluorescence collection for optimum signal-to-noise ratio. Light emitting diodes (LEDs) are used for the excitations and the intensity of each is modulated at a different frequency so that only a single photomultiplier tube is needed for fluorescence detection. Fourier transformation of the data isolates each component, separating the intrinsic fluorescence contributions resulting from the excitations. It is important to note that viable cells, dead cells, spores, and even media can be distinguished by these methods [11].

This instrument for fluids has a total of 10 LEDs- 4 amber, 4 red and 2 UV (Figure 1). The number and position of these LEDs with respect to the photomultiplier tube (PMT) are designed to give similar intensities of each fluorescence emission at the photomultiplier tube for a sample containing an equal amount of live cells and dead cells. Red and amber LEDs are positioned closer to the PMT since the absorption of their light in water is considerably higher than for UV. As sample flows through the instrument, the fluorescence emission is measured by the PMT, which uses an excitation rejection filter [13] to discriminate the fluorescence emission from the excitation light produced by the LEDs. The output of the photomultiplier tube is sent to the electronics, which analyzes the data as described above and communicates it to the GUI [13]

\section{Methods and Measurements}

\section{Preparation of live bacteria}

Bacillus thuringiensis (ATCC10792) was used to demonstrate realtime continuous detection of live and dead bacteria, as well as spores. For the preparation of live bacteria, bacteria were grown in Luria-Bertani broth (LB) (Sigma-Aldrich, MO) and sampled at the mid-log growth phase. Bacteria were centrifuged at 10,000 rpm for 5 minutes to obtain a pellet and subsequently washed three times in phosphate buffered saline solution (PBS) to remove any residual growth medium. To determine the total bacterial count, bacterial cells were suspended in PBS and counted using the Petroff-Hausser method [19] (Hausser Scientific, PA) as shown in Figure 3d. 1:10 serial dilutions were performed to obtain different concentrations of bacteria. Bacterial measurements were taken by sampling $1 \mathrm{ml}$ from each dilution into a water circulator containing $6 \mathrm{~L}$ of deionized water (DI water). A total of 25 measurements were averaged to obtain a single measurement for each dilution.

\section{Preparation of dead bacteria}

For the detection of dead bacteria, the same protocol for growth and sample preparation was used. To kill the bacteria, bacteria were treated with $10 \%$ bleach for 10 minutes after the three washes. Counts were performed as described above. However, instead of measuring $1 \mathrm{ml}$ aliquots, $0.2 \mathrm{ml}$ aliquots were dispensed into a water circulator. The measurements were performed as described above for live bacteria measurements. To confirm dead cells, a 1:10 serial dilution was performed and bacteria were plated in LB agar plates overnight at $37^{\circ} \mathrm{C}$.

\section{Spore preparation}

Bacillus thuringiensis was inoculated into $100 \mu \mathrm{l}$ of Difco sporulation medium and supplements $(D S M+S)$, and this was spread on a DSM+S plate. The plate was incubated for 6 hours at $37^{\circ} \mathrm{C} .5 \mathrm{ml}$ of $\mathrm{DSM}+\mathrm{S}$ was added to a light lawn, which was then scraped. Absorbance was measured at $600 \mathrm{~nm}$ to determine cell density, followed by inoculation of $0.1 \mathrm{ml}$ into a $1000 \mathrm{ml}$ flask and incubation overnight at $37^{\circ} \mathrm{C}$ at 150 RPM. Spores were collected by centrifuging and re-suspending in 
Citation: Kilungo AP, Carlton-Carew N, Powers LS (2013) Continuous Real-time Detection of Microbial Contamination in Water using Intrinsic Fluorescence. J Biosens Bioelectron S12: 002. doi:10.4172/2155-6210.S12-002

cold distilled water, and by washing 6 times using cold distilled water. Samples were stored in $\mathrm{PBS}$ at $4^{\circ} \mathrm{C}$. Crystal violet was used to stain the spores. Under the microscope, spores appeared to have a halo, as shown in Figure 5d and were also counted using the Petroff-Hausser method described above [19]. The measurements were performed in the same manner as the dead cell measurements, except the water temperature in the circulator was kept at $4^{\circ} \mathrm{C}$. In order to determine spore viability, spores were plated in triplicates after a 1:10 serial dilution and incubated overnight in $\mathrm{LB}$ agar plates at $37^{\circ} \mathrm{C}$.

\section{Results}

The results of the measurement of the intrinsic fluorescence as a function of concentration are shown below. Note that the excitation wavelength is shown in blue and DI water in red as annotated on the right of each graph. $\mathrm{R}^{2}$ is the square of the Pearson product moment correlation coefficient and is a measure of the goodness of the fitted line to the data. One standard deviation is indicated by the associated error bar for each point.

UV excitation, which is used primarily to monitor the increase in total microbial load, showed a linear increase in the log of the intrinsic fluorescence with the log of the live bacteria concentration (Figure 3a). The detection limit for live bacteria is $\sim 50$ cells/L. There was no change in the intrinsic fluorescence produced by red excitation within the error with the addition of live bacteria (Figure $3 b$ ) because this channel detects only spores and dead bacteria (Table 1). Amber excitation produces fluorescence from both live and dead cells (Table 1) and the results (Figure 3c) show a small increase in intrinsic fluorescence with the increase in live bacteria concentration (end points are outside 3 standard deviations).

\section{Live bacteria detection}

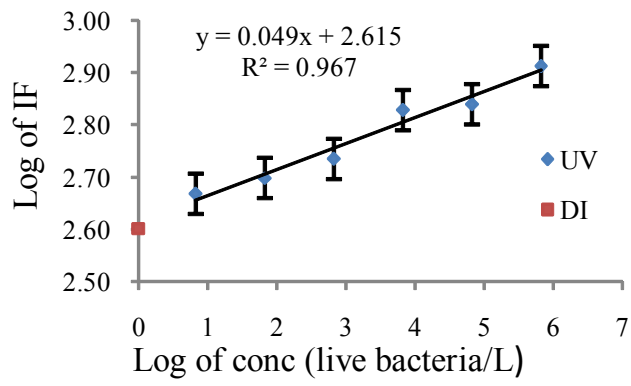

Figure 3a: Intrinsic fluorescence detection of live bacteria (Ex $365 \mathrm{~nm} /$ Em $440 \mathrm{~nm}$ ).

Live bacteria detection

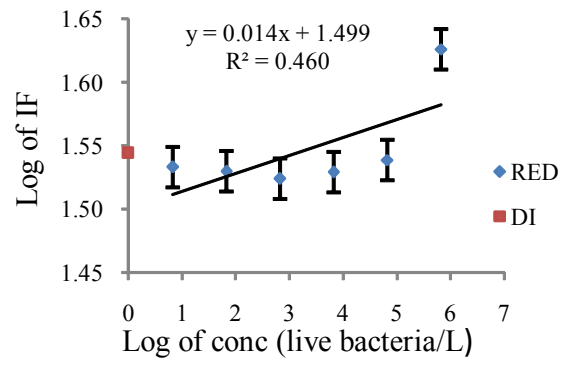

Figure 3b: Intrinsic fluorescence detection of live bacteria (Ex $635 \mathrm{~nm} /$ Em $770 \mathrm{~nm})$.

\section{Dead bacteria detection}

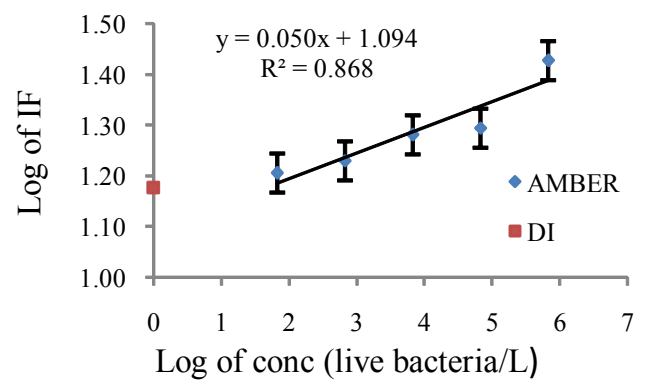

Figure 3c: Intrinsic fluorescence detection of live bacteria (Ex $590 \mathrm{~nm} /$ Em $675 \mathrm{~nm}$ ).

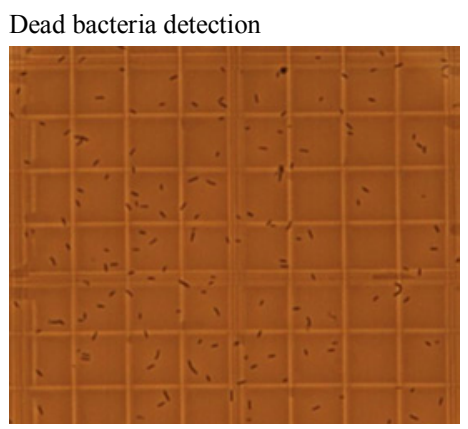

Figure 3d: Live Bacillus thuringiensis as seen under the microscope, using a Petroff-Hausser cell.

\begin{tabular}{|c|c|}
\hline Excitation/Emission & Contribution \\
\hline UV $($ Ex $365 \mathrm{~nm} / \mathrm{Em} 440 \mathrm{~nm})$ & 0.7 [live cells]+0.15 [dead cells] 0.15 [spores] \\
\hline amber $($ Ex $590 \mathrm{~nm} / \mathrm{Em} 675 \mathrm{~nm})$ & 0.5 [live cells]+0.5 [dead cells] \\
\hline red $($ Ex $635 \mathrm{~nm} / \mathrm{Em} 770 \mathrm{~nm})$ & 0.5 [dead cells]+0.5 [spores] \\
\hline
\end{tabular}

Table 1: Sources of contributions to intrinsic fluorescence signatures [13].

The detection limit for dead bacteria was much higher compared to that of live bacteria. This is likely due to fact that the harsh treatment used to kill the cells has damaged the fluorescent molecules and that the cells are not intact. No fluorescence below a concentration of $\sim 10^{8}$ dead bacteria/L was observed (Figures $4 \mathrm{a}, \mathrm{b}$ and $\mathrm{c}$ ). The UV fluorescence contains $\sim 15 \%$ dead cells (Table 1) while red and amber contain $50 \%$ dead cells. The observed changes in fluorescence with all three excitations are $\sim 3$ standard deviations of each other indicating little change.

Intrinsic fluorescence contribution from spores should be detected by the red excitation (50\%), but Figure $5 \mathrm{~b}$ shows no change larger than a single standard deviation. Some change may be observed with UV excitation (only $15 \%$ of which is due to spores while $70 \%$ is due to live cells, (Table 1)) as the first and final points (Figure 5a) are greater than 3 standard deviations. In the amber excitation (50\% live), the fluorescence of the beginning and end points in Figure $5 \mathrm{c}$ is is greater than 3 standard deviations. Taken together, these would support a conclusion that the spores had largely begun to germinate before and/or during the measurements.

\section{Discussion}

The results for live and dead bacteria measurements demonstrate the capability of the prototype instrument to detect live and dead cells in flowing water in real-time with a detection limit of $\sim 50$ bacterial 


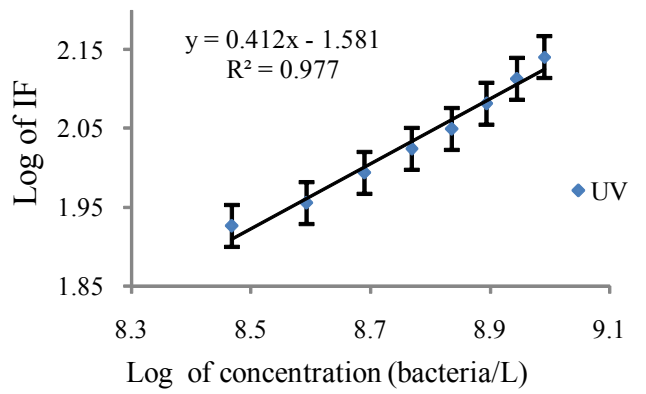

(DI reading $0,1.95)$

Figure 4a: Intrinsic fluorescence detection of dead bacteria (Ex $365 \mathrm{~nm} /$ Em $440 \mathrm{~nm}$ ).

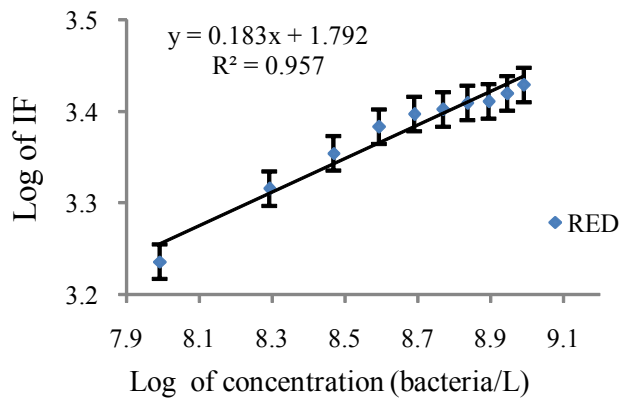

(DI reading 0, 3.2)

Figure 4b: Intrinsic fluorescence detection of dead bacteria (Ex $635 \mathrm{~nm} /$ Em $770 \mathrm{~nm}$ ).

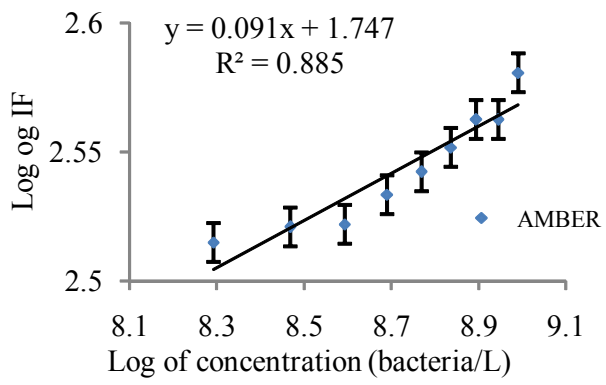

(DI reading $0,2.5$ )

Figure 4c: Intrinsic fluorescence detection of dead bacteria (Ex $590 \mathrm{~nm} /$ Em $675 \mathrm{~nm})$.

cells/L. There is a significant and reproducible increase in the UV excited intrinsic fluorescence (70\% of which is due to live cells) with the increase in the concentration of live bacteria. A small increase is observed in the amber-excited fluorescence (50\% of which is due to live cells). Killed bacteria may have had damaged fluorophores as little fluorescence change within the error is observed with concentration. While changes outside the error are observed in the fluorescence for spores, they are observed for the UV excitation (15\% of which is due to spores, $70 \%$ to live cells) and not for the red excited fluorescence (50\% of which is due to spores). This suggests that the spores had largely begun to germinate before and/or during the measurements.

There are two main reasons why the detection of spores as well as of dead bacteria in water may be difficult. First, the absorption coefficient

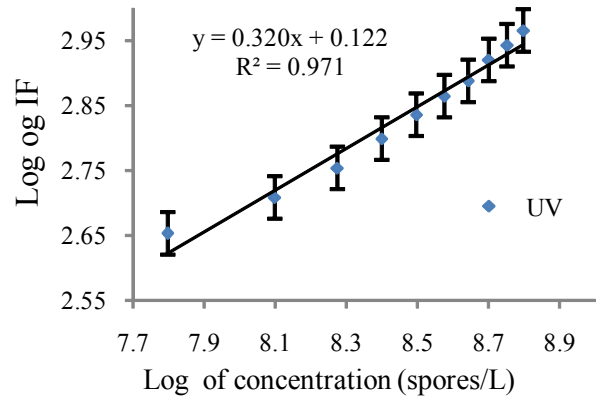

(DI reading $0,2.6)$

Figure 5a: Intrinsic fluorescence detection of spores (Ex 365 nm/Em 440 $\mathrm{nm}]$.

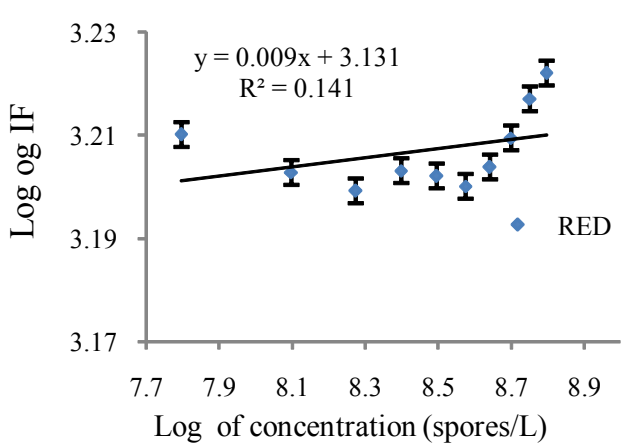

(DI reading 0, 3.2)

Figure 5b: Intrinsic fluorescence detection of spores (Ex 635 nm/Em 770 $\mathrm{nm}]$.

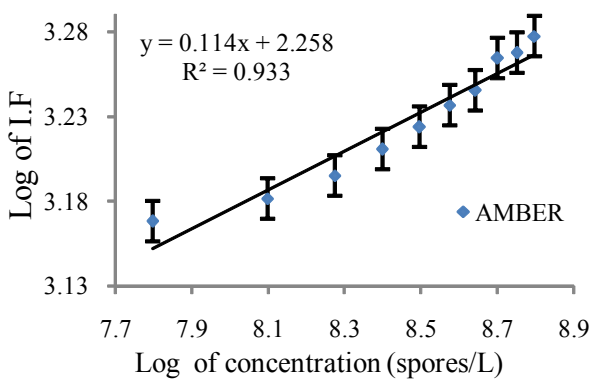

(DI reading $0,3.15)$

Figure 5c: Intrinsic fluorescence detection of spores (Ex 590 nm/Em 675 $\mathrm{nm})$.

of red light in pure, particle-free water is $\sim 1000$ times higher than the absorption coefficient of UV/blue light [20]. This means that most of the red light used for excitation and emitted as intrinsic fluorescence is absorbed by the water. Second, spores change morphology slowly compared to their metabolism. In our experiments in cold water $\left(4^{\circ} \mathrm{C}\right)$, we have observed spores to change metabolism to resemble that of a vegetative cell even though the morphology still superficially resembled that of a spore.

Even though amber excitation produces fluorescence from both live and dead bacteria (50\% each), this fluorescence is in the red and reduced by a factor $>100$ by water absorption. While the intensities 
Citation: Kilungo AP, Carlton-Carew N, Powers LS (2013) Continuous Real-time Detection of Microbial Contamination in Water using Intrinsic Fluorescence. J Biosens Bioelectron S12: 002. doi:10.4172/2155-6210.S12-002

Page 5 of 5

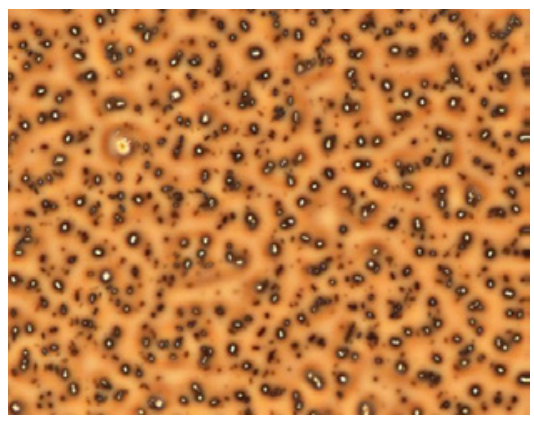

Figure 5d: Bacillus thuringiensis spores stained with crystal violet dye and viewed with a light microscope.

of the amber and red LEDs are significantly higher than that of the UV LEDs, this is not enough to compensate for the effects of water absorption in this prototype.

The use of intrinsic fluorescence has been demonstrated for the presence of live bacteria in water with a detection limit of $\sim 50$ cells/L. We were able to quantify the total microbial load and differentiate between dead and live bacteria for water-monitoring purposes. This technology, used together with direct microbial cell capture onto a ligand-coated surface may allow us to monitor our drinking water along the distribution water system continuously and determine the presence of pathogenic microbes $[11,13,18]$ in real-time.

\section{Acknowledgments}

A. Kilungo was supported in part by the Sloan Foundation and NSF BioME. The authors thank Dr. Walther Ellis for his critical discussions and advice on this project; Dr. Charles Gerba for the help and support and Miriam Eaton for her help with laboratory procedures. Thanks to David L. William for sharing his expertise in spore preparation; and Ambie Mobula for her general assistance.

\section{References}

1. Garrick D, Garfin GM, Jacobs K (2008) Models, assumptions, and stakeholders: Planning for water supply variability in the Colorado River basin. J Am Water Resour Assoc 44: 381-398.

2. Wildman R Jr, Forde NA (2012) Management of water shortage in the Colorado River basin: Evaluating Current Policy and the Viability of Interstate Water Trading. JAWRA Water Res Assoc 48: 411-422.

3. Christensen NS, Wood AW, Voisin N, Lettenmaier DP, Palmer RN (2004) The effects of climate change on the hydrology and water resources of the Colorado River basin. Climatic Change 62: 337-363.

4. Abbaszadegan M, Hasan MN, Gerba CP, Roessler PF, Wilson BR, et al. (1997) The disinfection efficacy of a point of use water treatment system against bacterial, viral and protozoan waterborne pathogens. Water Research 31: 574-582.

5. Keer JT, Birch L (2003) Molecular methods for assessment of bacteria viability $\mathrm{J}$ Microbiol Methods 53: 175-183.

6. Queiroz AP, Santos FM, Sassaroli A, Hársi CM, Monezi TA, et al. (2001) Electropositive filter membrane as an alternative for the elimination of PCR inhibitors from sewage and water samples. Appl Environ Microbiol 67: 46144618.

7. Call DR, Borucki MK, Loge FJ (2003) Detection of bacterial pathogens in environmental samples using DNA microarrays. J Microbiol Methods 53: 235243.
8. Weber G (1950) Fluorescence of riboflavin and flavin-adenine dinucleotide Biochem J 47: 114-121.

9. Lehrer SS, Kerwa G (1972) Intrinsic fluorescence of actin. Biochemistry 11 1211-1217.

10. Tretnak W, Wolfbeis OS (1989) Fully reversible fibre-optic glucose biosensor based on the intrinsic fluorescence of glucose oxidase. Anal Chem 221:195203.

11. Kim HY, Estes CR, Duncan AG, Wade BD, Clary FC, et al. (2004) Real-time detection of microbial contamination IEEE Eng Med Biol Mag 23: 122-129.

12. Estes C, Duncan A, Wade B, Lloyd C, Ellis W Jr, et al. (2003) Reagentless detection of microorganisms by intrinsicfluorescence. Biosens Bioelectron 18: 511-519.

13. Powers L, Ellis W Jr, Lloyd C (2012) Real-time In-situ detection of microbes. J Biosens Bioelectron S11:001.

14. Giana HE, Silveira L, Zangaro RA, Pacheco MTT (2003) Rapid identification of bacterial species by fluorescence spectroscopy and classification through principal components analysis. J Fluoresc 13: 489-493.

15. Leriche F, Bordessoules A, Fayolle K, Karoui R, Laval K, et al. (2004) Alteration of raw-milk cheese by Pseudomonas spp.: monitoring the sources of contamination using fluorescence spectroscopy and metabolic profiling. $J$ Microbiol Methods 59: 33-41.

16. Ammor MS (2007) Recent advances in the use of intrinsic fluorescence for bacterial identification and characterization. J Fluoresc 17: 455-459.

17. Roselle DC, Seaver M, Eversole JD (1998) Changes in intrinsic fluorescence during the production of viable but nonculturable Escherichia coli. J Ind Microbiol Biotechnol 20: 265-267.

18. Llyod CR, Cleary FC, Kim HY, Estes CR, Duncan AG, et al. (2003) Is what you eat and drink safe? Detection and identification of microbial contamination in foods and water. Proc IEEE Inst Electr Electron Eng 91: 908-914.

19. http://www.hausserscientific.com/products/petroff_hausser_counter.html

20. Effects of light absorption and scattering in water samples on OBS measurements. Campbell Scientific, Inc. 